\title{
LER, ESCREVER, PESQUISAR: uma metodosofia
}

\author{
Emilia Carvalho Leitão Biato \\ Karen Elisabete Nodari
}

\section{Resumo}

Os pesquisadores da Rede Escrileituras, ao criarem procedimentos inventivos de escritura em espaços autorais de aula, propuseram diferentes métodos de investigação para a tomada dos textos produzidos, movimento que os levou à acolhida do acontecimento, do imprevisível. Este estudo busca identificar as possibilidades investigativas de processos inventivos com a escrita, a partir da retomada de teses e dissertações produzidas no contexto da Rede Escrileituras no período de 2010 a 2018, de modo a ter uma visão de estado de conhecimento acerca dos percursos de pesquisa propostos. Nota-se, nos trabalhos estudados, que há uma disseminação dos sentidos das situações observadas por uma via de experimentações que unem a leitura, a escritura, a didática, o currículo e a formação de pesquisadores-professores e, em consequência, uma multiplicidade de modos na tomada da vida grafada nos espaços de aula.

Palavras-chave: método; escrileituras; aula; transcriação

\section{TO READ, TO WRITE, TO RESEARCH:}

a methodosophy

\begin{abstract}
The researchers from Rede Escrileituras when creating inventive writing procedures in Aula authorial space, proposed different investigation methods for taking the texts produced, movement that led them to welcome the event, the unforeseeable. This study demands to identify the investigative possibilities of inventive processes with writing, from the resumption of thesis and dissertations resulting from the Rede Escrileituras studies, from 2010 to 2018, in order to have a view of the state of knowledge about the proposed research paths. It is clear that there is a dissemination of the senses of the situations observed in the works studied through experiments that unite reading, writing, didactics, curriculum and formation of researchers-teachers and, in consequence, a multiplicity of ways in taking life written in the aula spaces.
\end{abstract}

Keywords: method; writreadings; aula; transcriation

\section{LEER, ESCRIBIR, INVESTIGAR: una metodosofia}

\section{Resuimen}

Los investigadores de la Red Escrilecturas, creando procedimientos de escritura inventivos en espacios autorales de aula, propusieron distintos métodos de investigación para tomar los textos producidos, movimiento que los llevó a la recepción del acontecimiento, de lo impredecible. Este estudio busca identificar las posibilidades de investigación de los procesos inventivos con la escritura, a partir de la reanudación de tesis y disertaciones producidas en el contexto de la Red Escrilecturas en el período 2010-2018, para tener una visión del estado del conocimiento sobre los caminos de investigación propuestos. Es notable, en los trabajos estudiados, que existe una difusión de los sentidos de las situaciones observadas, a través de experimentos que unen lectura, escritura, didáctica, currículum y formación de investigadores-docentes y, en consecuencia, una multiplicidad de formas en la vida escrita en los espacios de aula.

Palabras clave: método; escrilecturas; aula; transcreación 


\section{INTRODUÇÃO}

O valor aos gestos de leitura e escrita, na educação básica e no ensino superior, compõe a noção de Escrileituras - um conceito criado por Corazza (2007), que apresenta uma relação indissociável da escrita-pela-leitura ou da leitura-pela-escrita. A escrileitura expressa a potência de criação na produção do texto, como um modo de ensinar, aprender e investigar em meio à vida processos mobilizados por Oficinas de Transcriação ${ }^{1}$.

O desenvolvimento do projeto Escrileituras (CAPES/INEP) articulou quatro universidades públicas brasileiras - UFRGS, UNIOESTE, UFPEL e UFMT — num exercício de pesquisa e de ação junto a escolas de educação básica e a universidades. Devido à sua abrangência, conectividade e potencial criador, o projeto impulsionou a composição da Rede de Pesquisa Escrileituras da diferença em Filosofia-Educação em 2015. O projeto Escrileituras tinha como um de seus princípios, a noção da aula como prática de corpo inteiro, que envolve experimentações de leituras e escritas, entendidas como potências do pensamento e de uma postura multivalente do leitor, já que exerce, simultaneamente, a função de coautor. A proposta da escrita como escrileitura entende um texto como sempre aberto às interferências do leitor e, por isso, escrevível ou traduzível de diversas maneiras.

É um conceito, portanto, que insere as ações do projeto realizado numa dimensão imaginativa de todo texto, permitindo, a cada produção, um gesto de fruição. De fato, torna-se impossível despregar a escrileitura dos modos de atribuir sentidos, das vivências, das coisas, do mundo, dos modos de andar a vida, dos processos de criação. Buscam-se, justamente, as brechas, os espaçamentos deixados pelos "originais", por encontrar aí a riqueza da produção de si e do surgimento do novo.

A modalidade de ação proposta se desenvolveu através de oficinas de transcriação, espaços didáticos de aula, que tomaram a experimentação como condição necessária à aprendizagem, desde que funcionasse como convocação de estudantes e professores ao exercício do pensamento, de forma a traduzir criadoramente os objetos do conhecimento.

Cada oficina foi composta por alguma forma de convite à escrita e à leitura de histórias, poesia, música, telas, desenhos, problemas, romances, fantasias. Os processos disparadores da produção textual põem em cena algo a ser visto, observado, admirado, lido, dito, enunciado, questionado e transformado de modos diversos.

Nos diferentes cenários das propostas de oficinas de transcriação (OsT), evidencia-se o drama de saberes investigados: como tomar e analisar dados constituídos e observados ao longo e em meio a ações de Escrileituras? Estivemos atentos às diversidades das propostas, às irregularidades surgidas dos fazeres partilhados em oficinas e das variáveis apresentadas em alternativa à dimensão representacional, tanto em relação aos processos educativos, quanto no que tange aos modos de pesquisar.

Justamente por tomarem, por objeto de estudo, o acontecimento em aula e as produções escritas daí resultantes, os processos de pesquisa se caracterizaram como o que Jacques Derrida (2001, p. 231) chama de "[...] possibilidades impossíveis de dizer". As invenções, as possibilidades do novo, o que chega — como acontecimentos — ocupam o campo do imprevisível, do que não está dado e não pode ser dito de modo teórico, a não ser que os tratemos como o impossível. Uma vez que as aulas buscaram provocar experimentações do pensamento e o surgimento do novo na

\footnotetext{
${ }^{1}$ Oficinas de transcriação são espaços-tempos didáticos de aula, dedicados a possibilidades criadoras e à fluidez do pensamento. Podem ser de artes, filosofia, movimentos corporais, música, e sempre pretendem provocar o pensamento de forma inaugural, tendo em vista a produção de sentidos novos, mesmo para signos antigos e já conhecidos.
} 
forma de Escrileituras, seus produtos — objeto de pesquisa — podem ser entendidos como o impossível. A estrutura leitura-escritura em meio à vida carrega e assombra a possibilidade, pois sua vinda é absolutamente nova.

"Dizer o acontecimento é possível?”, o fato de que seja preciso responder por
vezes sim e não, deveria nos engajar a repensar todo esse valor de possibilidade
que marca nossa tradição filosófica ocidental... Um impossível que não é so-
mente impossível, que não é somente o contrário do possível, que é também a
condição ou a chance do possível. Um impossível que é a própria experiência do
possível. Para isso é preciso transformar o pensamento, ou a experiência, ou o
dizer da experiência do possível ou do impossível (DERRIDA, 2001, p. 244).

Em acolhida aos objetos possíveis e impossíveis — às simultaneidades — este trabalho tem, como objetivo, identificar diferentes abordagens investigativas dos processos inventivos com a escrita, a partir da retomada de saberes e fazeres, análises e estudos, a fim de compor uma visão de estado de conhecimento (SOARES, 1989) sobre os modos de observar, produzir e analisar nas pesquisas desenvolvidas na Rede Escrileituras, entre os anos de 2010 a 2018.

\section{PERCURSOS DESTE ESTUUDO}

Realizamos um levantamento dos métodos, ou melhor dizendo, da metodosofia de pesquisa utilizada para a produção das Escrileituras. Não se trata de um neologismo, longe disto, mas ao modo de Corazza (2020), uma vontade de se contrapor ao logos de todo o método, aquele que conduz sempre aos caminhos já conhecidos, como também de espremer as palavras, retorcer a língua e de fazer vibrar as práticas tradicionais de pesquisa em educação. Um movimento que está atento ao singular, ao traço distintivo, a uma pseudo-unidade de cada método de pesquisa, cujo efeito é falseador da revelação do baluarte da verdade. Movimento operacional que busca agregar, ao método, a sofia: "[...] um tipo de sabedoria plena de afectos e perceptos, literatura e arte, ciência e filosofia" (CORAZZA, 2020, p. 2). Para tanto, lançamos mão da produção decorrente da Rede, que está registrada em dissertações e teses, entre os anos 2010 e 2018. Importa destacar que a produção relacionada à Rede se encontra multiplicada em vários trabalhos, aos quais recorremos também em alguns momentos, para complementação.

Compusemos um estado da arte a partir do levantamento de pressupostos e procedimentos constituídos como percurso de pesquisa, na relação com cada objetivo dos estudos ligados às oficinas de transcriação. De acordo com Silva e Borges (2018), a pesquisa do tipo estado da arte ou estado do conhecimento apresenta seu valor relacionado à apresentação de pistas sobre como cada estudo foi realizado ao longo do tempo. Ainda Morosini et al (2014, p. 155) entendem o estado de conhecimento como:

[...] identificação, registro, categorização que levem à reflexão e síntese sobre a produção científica de uma determinada área, em um determinado espaço de tempo, congregando periódicos, teses, dissertações e livros sobre uma temática específica.

As autoras ainda destacam, nesse contexto, o valor do novo na pesquisa desse tipo. Especificamente, afirmam que a retomada de trabalhos já realizados com determinado tema permitem diversos desdobramentos, reflexões e retomadas.

Tomamos sete dos trabalhos de pós-graduação stricto sensu produzidos no contexto do andamento da Rede Escrileituras como objetos para nosso estudo, com foco na discussão metodosófica. Interessa-nos o percurso de pesquisa para a tomada e a análise da produção escrita nas aulas- 
oficinas. Retomamos cada um e selecionamos alguns elementos de referência, que podem expressar a diversidade de métodos qualitativos e procedimentos transcriadores adotados no contexto das pesquisas. São eles:

1. Método. Como o caminho pode ser nomeado e tecido no desenvolvimento do trabalho.

2. Conceitos mais relevantes que fundamentam o percurso da pesquisa. Uma característica da pesquisa qualitativa é, justamente, a clareza e o aprofundamento dos pressupostos teóricos que servem de sustentação para que se defina o mirante de observação e análise dos acontecimentos. Portanto, buscamos identificar essas bases no corpo das teses e dissertações.

3. Concepção de texto. Não obstante tivéssemos, todos, o pressuposto da compreensão do texto como produção partilhada em meio à vida - leitura pela escrita e escrita pela leitura —, há vários desdobramentos dessa concepção, que se manifestam nos modos como a tomada do texto em mãos pode ser proposta. Notamos, portanto, as especificidades da concepção de texto, a partir dos conceitos que foram operados.

4. Traços da pesquisa qualitativa. Buscamos destacar aspectos da definição de pesquisas qualitativas e as formas tomadas por esses aspectos, postos em relevância nos diferentes estudos. Destacamos, portanto, a observação dos acontecimentos em seu ambiente natural; a atenção aos detalhes; a experimentação dos pressupostos na composição da realidade; os papeis dos pesquisadores, dos professores, dos estudantes; as diferentes concepções de sujeito, entre outros. Assim, não tentamos encerrar os textos estudados nas categorias estritas do que se chama de pesquisa qualitativa. Ao contrário: buscamos apontar características que são caras a esse modo de pesquisar, especialmente em educação, com perspectivas e gestos que possam acrescentar e contribuir com sua composição.

5. Oficina de Escrileituras. Enfocamos as aulas na forma de oficinas de transcriação, em observação e discussão nos trabalhos, já que eram a fonte para a constituição dos dados das pesquisas.

\section{RESULTADOS: METODOSOFIA DE PESQUISA EM ESCRILEITURAS}

Larisa Bandeira (2014), com estudantes de EJA, realizou várias oficinas baseadas na experimentação de textos de Lou-Andreas Salomé, AnaïsNin e Tsvatáieva. O trabalho de Máximo Adó (2013) propôs a Oficina de Literatura Potencial e teve como foco dar mais atenção ao processo de criação do que aos resultados e tomá-los como o próprio acontecimento. Ambos, em contextos diversos, lançaram mão do método biografemático.

O conceito barthesiano de biografema é operado por Costa (2010) como método de intervenção e de investigação. A proposta é a de registrar, de forma escrita, os detalhes de uma vida, as raridades que passam despercebidas ou que ainda não foram significadas e partilhadas no plano cognitivo. Tomam-se, portanto, cortes (como os histológicos), trechos, palimpsestos da produção escrita. Ou seja, fragmentos do vivido capazes de transformar detalhes insignificantes (que não tinham significação anterior) em signos de escrita, e usar estes signos (especialmente aqueles que podem encantar o leitor) como disparadores de um outro texto. Trata-se da leitura-escritura de uma vida em experimentação e que, por isso, é produzida na potência da invenção de sentidos. O que é perseguido nesse método é, justamente, a invenção de si, entre imaginário e história biográfica.

Pretende-se, que tais dispositivos propiciem o ingresso no campo do vivido, das sensações e das invenções, o que implica, também, a passagem entre o tempo dos estoicos: cronos para aion, ou seja, o da duração. 
No planejamento das propostas, pretendeu-se dar valor ao vivido, especialmente às sensações e invenções, de modo que as faculdades dos participantes se comunicassem, não mais num sentido comum, mas entrassem num exercício disjuntivo, na exploração de deslocamentos. Esta subtração do logos como estrutura pronta e prévia, permitiu conectar o pensamento com o seu fora, o devir, com o surgimento de escritas intensivas e potentes (NODARI, CORAZZA, 2019).

A leitura do material produzido, na perspectiva biografemática (em correspondência com a OsT), traz, para esses textos, a noção de tessitura, uma costura cujos laços podem se fazer ou desfazer, além de inventar inúmeros sentidos.

Corazza (2010) afirma que não há possibilidade do biografema ser previamente determinado, pois realiza-se no percurso e em suas operações, pois toma, por objeto, as formas discursivas para, nessas linguagens, observar a vida atravessada pela obra e a obra atravessada pela vida. $\mathrm{O}$ conhecimento é tomado como criação e, portanto, o leitor (professor e pesquisador, nesse caso) é, também, autor do texto: “[...] a leitura biografemática faz irromper a figura do leitor, não como o curioso empírico, mas como o ator de uma escritura que já é, ela mesma, a realização de uma vida possível". (COSTA, 2010, p. 123).

Na tentativa de "[...] pegar uma vida de frente" (COSTA, 2010, p. 125), o pesquisador pega incidentes ou o ordinário ou o que o chama. Assim, a pesquisa biografemática não fixa as articulações entre vida e obra. Ao contrário: aponta para os aspectos mais ricos dessa relação.

A dissertação de Alessandra Azevedo (2013) tem, como destaque, traços de vivências nas produções escritas de um grupo de professoras da educação básica. A oficina de transcrição proposta foi o Phonodidaticário: encontros na forma de rodas de conversa acerca do papel da voz do professor e dos alunos, nos espaços-tempos da escola, serviram de provocação à escrita das professoras. O texto resultante, tomado como necessariamente biográfico, foi analisado com referência no método Otobiográfico.

Otobiografias é o título de uma obra de Jacques Derrida (2009), que registra uma conferência feita em 1976, na Universidade da Virgínia, por ocasião da celebração dos 200 anos da Declaração dos Direitos Humanos. Monteiro (2004) propõe o uso do termo otobiografia, como gesto de pesquisa em Educação, a partir da leitura de dossiês produzidos por formandas de Pedagogia. Firma a função do pesquisador, que escuta aguçadamente os textos, aquilo para o que já tem ouvidos, através de suas próprias vivências. Sendo assim, o método otobiográfico busca realizar uma escuta de vivências nos escritos, que passa, não necessariamente, pelas vivências de quem ouve. Afirma, portanto, os estilos de individuação que se constituem, conforme se misturam aos escritos (OLINI, MONTEIRO, 2016).

Ao discutir o método otobiográfico, Yatsugafu (2017, p. 95) afirma que as leituras, escrituras e, portanto, assinaturas, se inscrevem no biológico e no biográfico.

Todavia, as Ciências Humanas, historicamente, deixaram em um segundo plano - ou mesmo tentaram artificialmente deixar fora de seu fazer científico - a vida, as vivências dos sujeitos envolvidos na produção dos conhecimentos. Nas últimas décadas, entretanto, vemos muitas tentativas de fazer ciência tomando a vida como matéria, mas ainda precisamos romper com formas fragmentadas de conceber e racionalizar historicamente desenvolvidas na ciência.

Idalina Campos (2013, p. 13) propõe a oficina de transcriação Espiritografias de co-criação dialógicas, que se constituiu como "[...] um ateliê de experimentações espirituais e operatórias que primam pela elaboração do pensar, junção de três caóides - filosofia, ciência, arte - em ação dialógica e co-criativa". 
Os encontros com os participantes partiram de um problema — "Um diálogo o que é, para que serve?" (CAMPOS, 2013, p. 54) -, que funcionou como disparo ao exercício do pensamento a vasculhar e compor o diálogo através de textos literários. O gesto seguinte, e imbricado a este, foi o de dramatizar o conceito de diálogo, ganhando força criativa, como obra de arte.

A noção de eu que permeia este método é a do espírito como um eu funcional, um eu como uma função do pensamento, inseparável da matéria e aberto à produção de muitos eus. Nesse sentido, o interesse do pesquisador volta-se à riqueza da voz ou vozes que ressoam na escrita, "[...] volta-se para os mecanismos do pensamento-palavra, os quais possibilitam jogos e trocas que quebram os silêncios, abrindo espaço para a criação espiritual e seus ecos poéticos e epistemológicos." (CAMPOS, 2013, p. 77).

O método de dramatização constitui-se como uma forma de exploração conceitual, na qual o pesquisador, ao modo de Deleuze (2006a), não está interessado na sua definição, mas no seu movimento expresso pelas suas coordenadas espaço-temporais, sendo que as questões quem, como, quando e onde é que ganham importância - como num teatro, só que de ideias.

Por tratar-se de um método informe, não se poderia esperar uma fórmula pronta. Embora Idalina Campos tenha traçado alguns procedimentos, o fez de forma a estar aberta ao inesperado. O foco esteve nas percepções dos modos de existir, em suas intensidades, na observação dos devires de desejos, considerando que:

[...] espírito é mutável, fascinante, ele reverbera, desconstrói velhos conceitos, silencia e grita, mistura novas tintas, arrisca caminhos, becos, se hidrata nas fontes, pulsam veias de potência criativa, trajetórias compartilhadas diante da realidade, e com estes componentes, escreve (CAMPOS, 2013, p. 79).

Nesse sentido, o método de dramatização indaga pelas forças e pela vontade de potência, conforme o vínculo vida e obra e busca detalhes da vida compartilhada, como exercício de dramatização.

A dissertação de Josimara Schwantz (2015, p. 92) apresenta uma atividade cartográfica, no sentido de mapear subjetividades "[...] acionadas durante os rumos de uma vida", vida docente e suas rupturas com o que é estabelecido pelos métodos de alfabetização. Longe de pretender realizar um trabalho memorialístico, de busca por descobertas sobre a origem do ser, a autora se propôs a "[...] olhar atentamente para os deslocamentos". Seja "[...] dos lugares por onde passou, o que aprendeu e de que forma se instituiu". Para tanto, a cartografia possibilitou o contato com histórias, a partir da construção de territórios que definiram modos de aprender e de constituir-se professora. Caminhos intensivos e extensivos - mapas que assinalarão os lugares de um aprender: das formas e das forças de uma docente aprendiz.

A tese de doutorado de Emília Biato (2015) traz o método de Timpanização. As oficinas de transcriação propostas tinham a escola e a universidade como espaços e articulavam temas da saúde com a produção escrita — Oficina Cartas, Oficina cores, sabores e texturas e Oficina corpoescritura.

Tendo em vista o desenvolvimento do método de produção (nas Os'T) e de tomada dos textos, a autora se apropriou do gesto de timpanizar, de Jacques Derrida (1991): luxar o tímpano, romper com as marcas precisas estabelecidas entre o dentro e o fora, com o modo dualista de pensar sobre leitura e escritura, vida e morte, saúde e doença. Buscou, nas definições do método de pesquisa, a experimentação da morte da metafísica ocidental. Timpanizar, portanto, foi proposto como uma possibilidade de método de investigação. Materializou-se como uma forma de leitura inventiva de produções escritas sobre corpo e saúde. 
O método de timpanização compõe-se de três gestos: 1 . Tatear escombros, gesto pelo qual a desconstrução do pensamento dualista - estabelecido na metafísica ocidental - é afirmada. Por constatar essa desconstrução, os substratos que sobram servem à manipulação: os destroços da metafísica ocidental, as noções de absolutos e dogmas; 2. Disseminar sentidos, gesto pelo qual são multiplicados os sentidos das palavras. Instaura-se uma desconfiança em relação à fidelidade dos signos, que passam a ser tomados de forma a autorizá-los a serem inventados em novas leituras, interpretados como na afirmação nietzschiana "[...] interpretam-nos nossas vivências" (NIETZSCHE, 2012). Como o artista veste uma máscara e interpreta um personagem em cena, são propostos fantoches a mais ao texto escrito, em gesto de co-autoria; 3. Criar cadeias suplementares, gesto pelo qual cria-se, de fato, um novo texto, como quem se enche da vontade de escrever (BARTHES, 2005b) e, assim, tece Escrileituras de Escrileituras. Estabelecem-se nexos novos, que se agregam, em cadeia, pensamentos plenos que, juntos, extravasam, passam limites, assumem feições improváveis (BIATO et al, 2017).

E, por fim, a tese de doutorado de Fabiane Olegário (2018) arma um jogo que toma os fragmentos das escritas dos roteiros do grande arquivo (AE) produzido pelo projeto Escrileituras, bem como o arquivo formado por alunos dos cursos de Licenciaturas da UFRGS, entre 2016/1 e 2016/2, denominado de arquivo das licenciaturas (AL) como suas peças. Sendo que, o próprio movimentos das peças, ou melhor, é com os fragmentos das escritas que o plano será traçado, isto é, montado o tabuleiro onde as jogadas irão se desenvolver. Fragmentos a serem transcriados que foram subtraídos de outros textos - resquícios tão próximos e tão distantes de muitas vozes que ecoam e movem o pensamento enquanto escrevemos, valiosa fonte de vida e suas possibilidades. Neste sentido, Fabiane convida a jogar um jogo ideal, uma vez que ele pressupõe movimento, a ausência de regras pré-existentes, a afirmação de todo acaso a cada jogada fruto de um só e mesmo lançar, além de não acarretar em vencedores ou vencidos. Podemos dizer que é um jogo do problema e da pergunta.

Numa tentativa de dar a ver as dissertações e teses analisadas em relação ao método, apresentamos o quadro abaixo, que mostra um resumo das características observadas dos trabalhos em questão (Tabela 1).

Tabela 1: Resumo das metodosofias de pesquisa em Escrileituras

\begin{tabular}{|l|l|l|l|l|l|}
\hline \multicolumn{1}{|c|}{ Autor } & Método & Conceito chave & $\begin{array}{c}\text { Concepção de } \\
\text { texto }\end{array}$ & $\begin{array}{l}\text { Traços da pes- } \\
\text { quisa qualita- } \\
\text { tiva } \\
\text { (cf. Creswell, } \\
\text { 2014) }\end{array}$ & $\begin{array}{c}\text { Oficina de } \\
\text { Escrileituras }\end{array}$ \\
\hline $\begin{array}{l}\text { ADÓ, M. D. } \\
\text { L. (2013) }\end{array}$ & Biografema & $\begin{array}{l}\text { A literatura po- } \\
\text { tencial espera e } \\
\text { necessita do lei- } \\
\text { tor para realizar- } \\
\text { se plenamente }\end{array}$ & $\begin{array}{l}\text { O texto é como } \\
\text { um jogo que se } \\
\text { joga a dois, sem } \\
\text { que os dois ja- } \\
\text { mais se encon- } \\
\text { trem }\end{array}$ & $\begin{array}{l}\text { O pesquisador } \\
\text { se posiciona e } \\
\text { apresenta seus } \\
\text { valores no traba- } \\
\text { lho }\end{array}$ & $\begin{array}{l}\text { Oficina de Liter- } \\
\text { atura Potencial }\end{array}$ \\
\hline $\begin{array}{l}\text { AZEVEDO, } \\
\text { A. C. A. A. } \\
\text { (2013) }\end{array}$ & Otobiografia & $\begin{array}{l}\text { (PEREC; VA- } \\
\text { LÉRY) }\end{array}$ & $\begin{array}{l}\text { Otexto, inevita- } \\
\text { velmente, deixa } \\
\text { rastros de vivên- } \\
\text { cias de seu autor }\end{array}$ & $\begin{array}{l}\text { Atenção ao per- } \\
\text { curso de pes- } \\
\text { quisa, modifi- } \\
\text { cando questões } \\
\text { conforme o pro- } \\
\text { blema de pes- } \\
\text { quisa necessitava }\end{array}$ & Phonodidaticário \\
\hline
\end{tabular}


DOI: $10.12957 /$ teias.\%Y.53881

\begin{tabular}{|c|c|c|c|c|c|}
\hline $\begin{array}{l}\text { SCHWANT } \\
\text { Z, J. W. }\end{array}$ & Cartografia & $\begin{array}{l}\text { Escuta de vivên- } \\
\text { cias na voz e nos } \\
\text { escritos (NI- } \\
\text { ETZSCHE; } \\
\text { DERRIDA) }\end{array}$ & $\begin{array}{l}\text { Construção de } \\
\text { um território }\end{array}$ & $\begin{array}{l}\text { Apresenta, como } \\
\text { pressuposto } \\
\text { epistemológico, } \\
\text { aproximação } \\
\text { com os partici- } \\
\text { pantes }\end{array}$ & Filodança \\
\hline (2015) & Dramatização & $\begin{array}{l}\text { História de uma } \\
\text { vida }\end{array}$ & $\begin{array}{l}\text { Vida com- } \\
\text { partilhada }\end{array}$ & $\begin{array}{l}\text { Busca por deta- } \\
\text { lhes dos aconte- } \\
\text { cimentos }\end{array}$ & $\begin{array}{l}\text { Espiritografias } \\
\text { de cocriação dia- } \\
\text { lógica }\end{array}$ \\
\hline $\begin{array}{l}\text { CAMPOS, } \\
\text { M. I. K. } \\
(2013)\end{array}$ & Biografema & $\begin{array}{l}\text { (DELEUZE; } \\
\text { KASTRUP) }\end{array}$ & $\begin{array}{l}\text { Escrita de vida } \\
\text { aberta a novas } \\
\text { possibilidades de } \\
\text { dizer }\end{array}$ & $\begin{array}{l}\text { Afirma a ideia de } \\
\text { múltiplas realida- } \\
\text { des, tanto dos } \\
\text { pesquisadores } \\
\text { quanto dos parti- } \\
\text { cipantes }\end{array}$ & $\begin{array}{l}\text { Várias oficinas } \\
\text { biografemáticas }\end{array}$ \\
\hline $\begin{array}{l}\text { BANDEIRA } \\
\text {, L. V. V. } \\
(2014)\end{array}$ & Timpanização & Informe & $\begin{array}{l}\text { O texto abre } \\
\text { possibilidade à } \\
\text { disseminação de } \\
\text { sentidos }\end{array}$ & $\begin{array}{l}\text { Experimenta } \\
\text { preceitos e pres- } \\
\text { supostos na ob- } \\
\text { servação dos } \\
\text { acontecimentos }\end{array}$ & $\begin{array}{l}\text { Oficina Fantasias } \\
\text { em cores, sabores e } \\
\text { texturas; Oficina } \\
\text { corpo-escritura; Ofi- } \\
\text { cina Cartas }\end{array}$ \\
\hline $\begin{array}{l}\text { BIATO, E. } \\
\text { C. L. (2015) }\end{array}$ & Agenciamento & $\begin{array}{l}\text { (DELEUZE; } \\
\text { VALÉRY) }\end{array}$ & $\begin{array}{l}\text { O leitor/jogador } \\
\text { é levado a repetir } \\
\text { o texto, fantasi- } \\
\text { ando-o mais uma } \\
\text { vez, de modo } \\
\text { que os afetos } \\
\text { produzidos no } \\
\text { decorrer da lei- } \\
\text { tura sejam extra- } \\
\text { polados e produ- } \\
\text { zam textos trans- } \\
\text { criados }\end{array}$ & $\begin{array}{l}\text { Os arquivos her- } \\
\text { dados serão tra- } \\
\text { balhados de } \\
\text { modo crítico, se- } \\
\text { letivo e criador }\end{array}$ & $\begin{array}{l}\text { Arquivos dos } \\
\text { quatro núcleos } \\
\text { de Escrileituras e } \\
\text { das Licenciaturas } \\
\text { da UFRGS entre } \\
2016 / 1 \text { e } 2016 / 2\end{array}$ \\
\hline
\end{tabular}

Fonte: BIATO; CORAZZA; NODARI, 2019.

\section{DISCUSSÃO: TRÊS MARGENS METODOSÓFICAS}

Como eram muitos apanhados de diferentes e múltiplas vivências, cada movimento de aproximação investigativa ganhou nuances próprias. Os objetos de estudo - embora comuns em aspectos como a realização de aulas como oficinas, o foco nas Escrileituras, o uso de elementos imaginativos, o empenho por melhorar o IDEB na escola - , puxaram, eles mesmos, vias de pesquisa, e firmaram diferentes mirantes de investigação.

Diante das perspectivas que compõem o pensamento nas pesquisas estudadas aqui, frente ao material que foi produzido em exercício de olhos, ouvidos e mãos (NIETZSCHE, 2011), acolheu-se a composição de uma pesquisa do possível e do impossível. Pesquisamos o impossível e, portanto, encontramo-nos em um lugar marginal. Margens caracterizam-se como espaços de definição pouco clara: diferente das marcas, que se apresentam com precisão e definem limites claros, como o dentro e o fora, as margens deixam penetrar, são provisórias, permeáveis. Por habitarem margens, as Escrileituras se apresentam em "[...] fachos de olho" (FOUCAULT, 2006, p. VII), e é necessário que se assuma o perspectivismo como modo de interpretá-las (BIATO, 2015, p. 40).

Ocupando esse lugar pantanoso e impreciso, elegemos aqui três margens como mirantes para, a partir deles, discutir os métodos de pesquisa estudados aqui: 1 . A vontade e a necessidade de escrever; 2. Datar é assinar; 3. Nome de morto. 
A vontade e a necessidade de escrever

Parece ter havido um empenho na escolha e na proposição de métodos capazes de dar a ver a vontade de escrever (BARTHES, 2005b) e, ao mesmo tempo, da necessidade de escrever. A vontade de escrever caracteriza a leitura faminta de quem toma o texto de forma encantadora e provocadora do impulso de escrever. O passar dos olhos chama as mãos, num desejo de compartilhar a autoria - " "...] porque eu não a fiz eu mesmo... quero juntar-me ativamente ao que é belo" (BARTHES, 2005b, p. 14).

A autocomédia do intelecto não se interessa por uma história da verdade; mas por uma narrativa de sua própria potência como contingência de composição. Um escrever que funcione, apenas, como experimento do trabalho de alguém que escreve (ADÓ, 2013, p. 39).

Máximo Adó (2013) apresenta o escrever como narrativa de potência e como experimento de quem escreve. Ao dispararem movimentos tradutórios, as oficinas de transcriação realizaram um movimento livre da fixação dos sentidos originais das matérias ou conhecimentos prévios, de forma a provocar a vontade de escrever em modos novos de dizer e ensinar as coisas, como experimento. Tanto os pesquisadores quanto os participantes das oficinas foram instigados a traduzir elementos do vivido em articulação com provocações de leitura; foram ações que incluíram amarrações de sentidos, em nexos improváveis.

Assim, o trabalho de Adó apresenta, como sua precondição, três características do gesto de escrever: escrever como um escritor clássico, escrever atento às próprias regras (criadas) e escrever - pois isso consiste em experimentar a Educação - em ideias que sucedem umas às outras.

A vontade de escrever é um valor expresso nos percursos das pesquisas. No entanto, de forma indissociada, a necessidade de escrever também transparece como objeto de estudo e os métodos de investigação precisam dar a ver esse elemento. "A literatura potencial é aquela que espera um leitor, aquela que o espera e o necessita para realizar-se plenamente" (ADÓ, 2013, p. 74), já que um texto precisa do escritor tanto quanto um escritor necessita escrever.

Fabiane Olegário concebe o leitor como jogador, pois ao ler lança mão de estratégias inventadas para compor novas cenas para o texto. Sendo que é pela via da leitura que as palavras ganham vida. De modo que ao ler, o leitor abandona, imediatamente, o papel de espectador, ou melhor, o texto convoca o leitor a integrar a cena. "É o leitor quem movimenta as linhas do texto, dá ritmo às palavras, mobiliza a sonoridade das letras, rouba pedaços aqui e ali. [...] O leitor toma as palavras como pequenos dados capazes de inúmeras possibilidades combinatórias (OLEGÁRIO, 2018, p. 17). Uma vez que é da própria natureza do texto viver em mãos alheias, como o jogo do anel, que passa de mão em mão, a convocar o leitor a compor com os fragmentos, a produzir um novo texto. Portanto, leitura nunca estará desvinculada da escritura. Há nessa relação um jogo em que leitor-jogador cria para si determinadas regras quando lê e escreve, mediante movimentos operados por duplas capturas que ocorrem entre leitor-escritor e o texto.

Ao ser perguntado sobre a riqueza de seus objetos, criados como obras de arte, Bispo do Rosário afirma que não se deleita em suas manufaturas, não funcionam como uma escrita de prazer (BARTHES, 1987). Relata que tudo o que faz, só faz porque precisa. Recebe ordens da santa e obedece, como vemos numa entrevista com ele: “[...] eu escuto uma voz, e é essa voz que me obriga a fazer tudo isso... eu recebo as ordens e sou obrigado a fazer" (HIDALGO, 2012, p. 273).

De modo semelhante, Rainer Maria Rilke (2006, p. 25) sugere a um jovem poeta que ele se questione profundamente na madrugada: “[...] preciso escrever?”. E que investigue o mais íntimo 
de seu coração, para sondar se morreria, caso fosse proibido de escrever. Se a resposta fosse afirmativa, então, que construísse toda a vida em função dessa necessidade.

Os métodos das oficinas e, por conseguinte, os métodos de pesquisa adotados, queriam criar e ver a necessidade de escrever. Larisa Bandeira (2014, p. 29) escolhe os textos a serem usados na oficina a partir de alguns critérios, dentre eles os que abriam questões:

De qualquer gênero, os textos que possibilitaram a formulação de questões eram os que, quando percebiam a inexistência de problemas, os criavam durante a leitura de suas palavras; os que atacaram e foram atacados pela necessidade exigente de anotações nas orelhas da folha, pelo sublinhar de suas linhas, pelo levantar das cabeças durante a leitura.

$\mathrm{Na}$ resenha de Ainda escrever, Biato (2018) afirma que se trata de um livro que se lê levantando a cabeça, justamente pelo correr de ideias, pelo que instiga, por suas conexões e suscitar de vozes. Importa despertar a vontade de escrever e, de forma quase imperativa, suscitar abertura de caminhos à necessidade vital de escrever.

\section{Datar é assinar}

A expressão "datar é assinar" é de Jacques Derrida, na conferência Otobiografias (DERRIDA, 2009, p. 41). A data que, naturalmente, estabelece um marco e define um limite, aqui toma a feição da assinatura de um nome supostamente próprio. Cada oficina estabeleceu, a priori, diversos procedimentos e pressupostos a serem adotados e realizados no contato com os participantes. Embora haja alguma dureza de planejamento de ações, traçado de objetivos e expectativas de resultados; embora existam datas - espaços e tempos - , essas se caracterizam como gestos. Datar é assinar. E uma assinatura é sempre a performance de alguém, seu modo singular de dizer e afirmar o que disse, de rascunhar e rabiscar um nome criado. São "[...] supostamente próprios" os nomes assinados (DERRIDA, 2009, p. 13), justamente por carregarem as vias inventivas do tornar-se o que se é.

Nota-se, aqui, que os métodos de produção de dados — os dados não existiam a priori, mas foram se constituindo no decorrer da pesquisa-ação — surgem da realização de oficinas, entendem a escrita como inseparável da leitura, e a escrileitura como inseparável da vida. Nesse sentido, são identificadas algumas datas: as oficinas marcadas e o texto tomado como objeto de estudo, potente para articular teoria (que fundamenta o projeto) com prática (de aula, de investigação, de pensamento). De modo que, as pesquisas desenvolvidas destacam o tempo da vida, o tempo do relato da vida, da escritura da vida pelo vivente, enfim, a data da autobiografia (DERRIDA, 2009).

A consideração de que datar é assinar levanta o caráter inventivo de cada oficina proposta. Vê-se, nesse sentido, tanto a necessidade quanto a possibilidade de lançar mão de métodos de pesquisa diversos, de forma a atender a análise dos diferentes dados constituídos.

A questão é que não há possibilidade de assinar sem deixar rastros da letra e dos movimentos do corpo. Vimo-nos, portanto, diante do desafio de articular as ações inventivas das Os'T com princípios metodosóficos investigativos.

Vale lembrar a discussão feita por Denise Gastaldo (2012) sobre pesquisadores que se encontram com a tarefa de explorar alternativas para "[...] pensar, falar e [...] remodelar as metodologias de pesquisa, para que elas não se constituam como ferramentas de reprodução social" (GASTALDO, 2012, p. 10). Foi o que os pesquisadores realizaram: observaram as produções de aula, e as estudaram, investigaram, refletiram sobre elas — gestos de quem assina com um nome supostamente próprio. 
Nome de morto

Opera-se com uma assinatura de quem escreve, numa lógica de vivente (DERRIDA, 2009). No entanto, importa dizer que o vivente é a aquele que tem vivências e que essas servem de alimento aos instintos e ao tornar-se o que se é (NIETZSCHE, 1995); que não controlamos e nem racionalizamos as vivências, mas ainda assim, é possível associar o viver com o inventar (NIETZSCHE, 2004); que a frase eu vivo pressupõe a morte do vivente, pois a vida é trágica - nada me pertence e as coisas mesmas sempre me escapam - e no momento em que chamamos o nome do vivente, o portador desse nome já está morto.

Nossas pesquisas estudam o vivente e, portanto, inclui-se aí, um movimento aditivo — vida e morte. Em um esforço minucioso, lidamos com um nome de morto, com os personagens criados e as ficcionalidades do vivente. Destaca-se, portanto, que os métodos estudados aqui não se colocam em busca de um querer dizer, de desvelamentos, e nem da verdade.

Por exemplo, há um empenho do método biografemático em discernir vidarbos - a vida não justifica a obra, mas é sobreposta à obra que atravessa a vida (CORAZZA, 2010). Sua matéria se compõe de indiscerníveis vividos e escritos. O método de timpanização se propõe a ocupar lugares marginais - sem limites precisos - tendo em vista a observação de objetos indecidíveis, como forças constituidoras de si, sempre em luta, como saúde e doença, vida e morte, leitura e escritura (BIATO, 2015).

No caso das pesquisas em estudo aqui, há um esforço de superação da busca por identidades - a identidade associada com a generalização (DELEUZE, GUATTARI, 2006b) — em direção à "[...] audácia de pensar a docência diferentemente do que já se pensou ou se pensa [...] em seus efeitos e experimentações imprevisíveis" (CORAZZA, 2018, p. 4). Para tanto, ocupam-se lugares marginais - a margem, diferentemente da marca, não tem limite preciso — segue-se o conselho derridiano de procurar "[...] los bordes, los tabiques, los corredores" (DERRIDA, 2009, p. 40). Buscam-se as bordas - margens - as partições - e também os cortes, os palimpsestos de que diz Barthes (2005a) —, os corredores - trechos, pedaços, minúcias. Sempre com olhos, ouvidos e mãos aguçados.

\section{CONSIDERAÇÕES FINAIS}

Das três margens ocupadas para discutirmos a metodosofia de pesquisa em Escrileituras, parece nítido que os estudos que apresentam influências nietzschianas, pós-estruturalistas e pensamento da diferença levantam a necessidade de modos correspondentes de questionar, tomar e analisar (MEYER, PARAÍSO, 2012). Reconhece-se que o propósito de Nietzsche, Derrida, Deleuze; Guattari e Barthes não foi o de estruturar métodos de pesquisa, no entanto, suas obras inspiram diversos modos de observação de acontecimentos, ensaios de perspectivas e experimentação do pensamento. Nesse sentido, seus pressupostos servem à constituição de métodos de investigação. Trata-se de pressupostos que necessariamente mobilizam o pensamento e demandam empenho "[...] de invenção e ressignificação" (MEYER, PARAÍSO, 2012, p. 23).

Ao pesquisador, coube a tarefa de criar métodos como um trabalho ficcional que, segundo Olegário (2018), envolve um desfazer, refazer e fazer, ou seja, arranjos territoriais impulsionados pelo desejo a originar um novo território pleno de agenciamentos (DELEUZE, GUATTARI, 2011).

A pesquisa foi tomada, portanto, como a experiência labiríntica de Ariadne, noiva de Dioniso. A Ariadne, que por um lado, diz da figura moderna, cartesiana, aponta, também, para outras lições: escutar palavras que criam sentido, que produzam o novo, que façam surgir o inédito. Passa, 
portanto, a um percurso labiríntico, como criadora de caminhos, de perspectivas, de múltiplas faces que falam das coisas, das ideias e dos valores (MONTEIRO, BIATO, 2008). Com isso, produzir conhecimento a partir da pesquisa se configura mais como criação do que descoberta. Na experiência com pesquisa em leitura-escritura, nota-se a impossibilidade de se tomar em absoluto os objetos das investigações, pois foi perceptível que as oficinas suscitaram diferentes pontos de vista, diversos caminhos e, portanto, maior riqueza na produção de conhecimento.

Os seis trabalhos abordados aqui apresentaram metodosofias de pesquisa diversos e diferentes usos destes - Biografema, Otobiografia, Cartografia, Timpanização e Dramatização. As metodosofias se mostraram úteis para a observação de elementos como a vontade e a necessidade de escrever, para destacar a assinatura performativa dos textos, em traços simultâneos de vivências e de morte, com destaque para ao caráter autobiográfico de toda produção escrita: potências de escrever, ensinar, aprender e afirmar a vida.

\section{REFERÊNCIAS}

ADÓ, Máximo Daniel Lamela. Educação potencial: autocomédia do intelecto. 194f. Tese, Doutorado em Educação. Universidade Federal do Rio Grande do Sul, Porto Alegre, 2013. Disponível em https://lume.ufrgs.br/handle/10183/69921. Acesso em 18 nov. 2020.

AZEVEDO, Alessandra Christina Abdala. A voz acena: a presença da voz na cena da aula. $155 f$. Dissertação, Mestrado em Educação, Universidade Federal de Mato Grosso, Cuiabá, 2013.

BANDEIRA, Larisa da Veiga Vieira. Um modo de ler e escrever na EJA: oficinas biografemáticas. 110p. Dissertação, Mestrado em Educação, Universidade Federal do Rio Grande do Sul, Porto Alegre, 2014.

BARTHES, Roland. Trad. J. Guinsburg. O prazer do texto. São Paulo: Perspectiva, 1987.

BARTHES, Roland. A preparação do romance I: da vida à obra. Notas do curso no Collège de France 1978-1979. Trad: Leyla Perrone-Moysés. São Paulo: Martins Fontes, 2005a.

BARTHES, Roland. A preparação do romance II: a obra como vontade. Notas do curso no Collège de France 1979-1980. Trad: Leyla Perrone-Moysés. São Paulo: Martins Fontes, 2005b (Coleção Roland Barthes).

BIATO, Emília Carvalho Leitão; CORAZZA, Sandra Mara; NODARI, Karen Elisabete. Escrileituras: ler-escrever como método de invenção no ensino e pesquisa. In: 8 . Congresso Ibero-americano de investigação qualitativa/8 CIAIQ 2019, 2019. Lisboa. Atas do 8 Congresso de Investigação Qualitativa. Aveiro/Portugal: Ludomidia, 2019. v. 1 p. 360-369. Disponível em https://proceedings.ciaiq.org/index.php/CIAIQ2019/article/view/2106. Acesso em 14 abr. 2020.

BIATO, Emília Carvalho Leitão. Oficinas de escrileituras: possibilidades de transcriação em práticas de saúde, educação e filosofia. 177f. Tese, Doutorado em Educação. Universidade Federal de Mato Grosso, Cuiabá, 2015.

BIATO, Emília Carvalho Leitão; LEITÃO, Cláudio Correia. Suplementos de escrituras. De errâncias e destinos. Rev. Polis e Psique, 7(1), p. 149-166, 2017a. Disponível em https://doi.org/10.22456/2238-152X.71963. Acesso em 16 maio 2020.

BIATO, Emília Carvalho Leitão Biato. Ainda escrever, de Luciano Bedin da Costa. (resenha). Revista Z Cultural (UFRJ), n. 1, 2018. Disponível em http://revistazcultural.pacc.ufrj.br/ainda-escrever-de-luciano-bedin-da-costa/. Acesso em 16 maio 2020. 
CAMPOS, Maria Idalina Krause. Alfabeto espiritográfico: escrileituras em educação. 95p. Dissertação, Mestrado em Educação, Universidade Federal do Rio Grande do Sul, Porto Alegre, 2013. Disponível em https://lume.ufrgs.br/handle/10183/70246. Acesso em 18 nov. 2020.

CORAZZA, Sandra Mara. Os cantos de Fouror: Escrileituras em filosofia e educação. Porto Alegre, Brasil: UFRGS: Sulina, 2007.

CORAZZA, Sandra Mara. Introdução ao método biografemático. In: FONSECA, Tânia Mara Galli; COSTA, Luciano Bedin da. Vidas do fora. Habitantes do silêncio. Porto Alegre: UFRGS, 2010, p. 85-107.

CORAZZA, Sandra Mara. Inventário de procedimentos didáticos de tradução: teoria, prática e método de pesquisa. Rev. Bras. Educ., Rio de Janeiro, v. 23, e230032, 2018. Disponível em https://dx.doi.org/10.1590/s1413-24782018230032. Acesso em 22 abr. 2020.

CORAZZA, Sandra Mara (org.). Métodos de transcriação: pesquisa em educação da diferença. São Leopoldo: editora Oikos, 2020. Disponível em https://www.ufrgs.br/ Escrileiturasrede/metodos/ Acesso em 12 jul. 2020.

COSTA, Luciano Bedin da. Biografema como estratégia biográfica: escrever uma vida com Nietzsche, Deleuze, Barthes e Henry Miller. Tese, Doutorado em Educação, Universidade Federal do Rio Grande do Sul, Porto Alegre, Brasil, 2010. Disponível em https://lume.ufrgs.br/handle/10183/27673

CRESWELL, John. Investigação qualitativa e projeto de pesquisa: escolhendo entre cinco abordagens. Trad. Sandra Mallmann da Rosa. Porto Alegre: Penso. Edição para Kindle, 2014.

DELEUZE, Gilles. O método de dramatização. In: DELEUZE, Gilles. A ilha deserta: e outros textos. Trad. Luiz B. L. Orlandi. São Paulo: Iluminuras, 2006a, p. 131-154.

DELEUZE, Gilles; GUATTARI, Félix. Diferença e repetição. Trad. Luiz Orlandi e Roberto Machado. 2. ed. Rio de Janeiro: Graal, 2006b.

DELEUZE, Gilles; GUATTARI, Felix. Mil platôs: capitalismo e esquizofrenia. v. 2. Trad. Ana Lúcia de Oliveira e Lúcia Cláudia Leão. 2. ed. São Paulo: Editora 34, 2011.

DERRIDA, Jacques. Margens da filosofia. Trad. Joaquim Torres Costa e Antônio Magalhães. Campinas, Brasil: Papirus, 1991.

DERRIDA, Jacques. Posições. Trad. Tomaz Tadeu da Silva. Belo Horizonte: Autêntica, 2001.

DERRIDA, Jacques. Otobiografías. La enseñanza de Nietzsche y la política del nombre propio. Trad. Horacio Pons. Buenos Aires: Amorrortu, 2009.

DERRIDA, Jacques. Uma certa possibilidade impossível de dizer o acontecimento. Revista Cerrados, 21(33). Trad. Piero Eyben. 2012. Recuperado de https://periodicos.unb.br/index.php/cerrados/article/view/26148.

GASTALDO, Denise. Pesquisado/a desconstruído/a e influente? Desafios da articulação teoriametodologia nos estudos pós-críticos. In: MEYER, Dagmar Estermann; PARAÍSO, Marlucy Alves. Metodologias de pesquisas pós-críticas em educaşão. Belo Horizonte: Mazza Ed., 2012, p. 9-13.

HIDALGO, Luciana. Arthur Bispo do Rosario - O senhor do labirinto. Rio de Janeiro: Rocco Digital. (eBook), 2012.

MEYER, Dagmar Estermann; PARAÍSO, Marlucy Alves. Metodologias de pesquisas pós-críticas em educação. Belo Horizonte: Mazza Edições, 2012.

MONTEIRO, Silas Borges. Quando a pedagogia forma professores. Uma investigação otobiográfica. Tese, Doutorado em Educação. Universidade de São Paulo, 2004. 
MONTEIRO, Silas Borges; BIATO, Emília Carvalho. Uma avaliação crítica acerca de método e suas noções. Revista de educação pública. 17 (34), p. 255-271, 2008.

MOROSINI, Marília Costa; FERNANDES, Cleoni Maria Barbosa. Estado do Conhecimento: conceitos, finalidades e interlocuções. Educação Por Escrito, 5(2), 154-164, 2014. Disponível em https://doi.org/10.15448/2179-8435.2014.2.18875. Acesso em 22 jun. 2020.

NIETZSCHE, Friedrich Wilhelm. Ecce homo: como alguém se torna o que é. Tradução, notas e posfácio: Paulo César de Souza. São Paulo: Companhia das Letras, 1995.

NIETZSCHE, Friedrich Wilhelm. Aurora. Trad. Paulo César de Souza, São Paulo: Companhia das letras, 2004.

NIETZSCHE, Friedrich Wilhelm. Assim falou Zaratustra: um livro para todos e para ninguém. Tradução, notas e posfácio: Paulo César de Souza. - São Paulo: Companhia das Letras, 2011.

NIETZSCHE, Friedrich Wilhelm. Fragmentos póstumos. Disponíveis em http://www.nietzschesource.org/. Acesso em fev. 2012.

NODARI, Karen Elisabete Rosa; CORAZZA, Sandra Mara. Um drama no currículo: oficinas de transcriação. Educação. Revista do Centro de Educação da UFSM, Santa Maria, 44, 1-21, 2019. Disponível em http://dx.doi.org/10.5902/1984644431380. Acesso em 13 maio 2020.

OLEGÁRIO, Fabiane. 244f. Jogo com arquivos: procedimentos didático-tradutórios. Tese, Doutorado em Educação, Universidade Federal do Rio Grande do Sul, Porto Alegre, 2018. Disponível em https://lume.ufrgs.br/handle/10183/182461.

OLINI Polyana Cíndia; MONTEIRO, Silas Borges. Sobre escritura e arte do estilo: aproximações otobiográficas. In: CORAZZA, Sandra Mara; ADÓ, Máximo Daniel L.; OLINI, Poliana Cíndia. Caderno de notas 9: Panorama de pesquisa em Escrileituras: Observatório da Educação. Porto Alegre: UFRGS/Doisa, 2016.

SCHWANTZ, Josimara Wikboldt. Biografemário de um aprender: Escrileituras em meio à vida. $110 \mathrm{f}$. Dissertação, Mestrado em Educação, Universidade Federal de Pelotas. Pelotas, 2015.

SILVA, Francisco Thiago; BORGES, Lívia Freitas Fonseca. Currículo e ensino de História: um estado do conhecimento no Brasil. Educ. Real., Porto Alegre, v. 43, n. 4, p. 1693-1723, out. 2018. Disponível em http://dx.doi.org/10.1590/2175-623676735. Acesso em 16 mar. 2020.

RILKE, Rainer Maria. Cartas a um jovem poeta. Trad. Pedro Sussekind. Porto Alegre: L\&PM, 2019.

SOARES, Magda. Alfabetização no Brasil- o estado do conhecimento. Brasília: INEP/MEC, 1989.

YATSUGAFU, Rubia Helena Naspolini Coelho. Investigação otobiográfica: composição de pesquisa em educação. 145 f. Tese, Doutorado em Educação. Universidade Federal de Mato Grosso, 2017.

\section{Informações das autoras}

Emília Carvalho Leitão Biato

Universidade de Brasília 
E-mail: emiliacbiato@yahoo.com.br

ORCID: https://orcid.org/0000-0002-4358-4558

Link Lattes: http://lattes.cnpq.br/1776414386448708

Karen Elisabete Rosa Nodari

Pesquisadora da Rede Escrileituras da Diferença e Filosofia-Educação: REDIF (CNPq/UFRGS) e DIF Artistagens, Fabulações, Variações (CNPq/UFRGS)

E-mail:kernodari@gmail.com

ORCID: https://orcid.org/0000-0002-5027-4857

Link Lattes: http://lattes.cnpq.br/6164914852306755 